\title{
Numerical analyses of stone column installation in Bothkennar clay
}

\author{
J. Castro
}

University of Cantabria, Santander, Spain

M. Karstunen

Chalmers University of Technology, Gothenburg, Sweden \& University of Strathclyde, Glasgow, UK

N. Sivasithamparam

University of Strathclyde, Glasgow, UK \& Plaxis B.V, Delft, The Netherlands

C. Sagaseta

University of Cantabria, Santander, Spain

ABSTRACT: The paper presents the results of numerical simulations studying the installation effects of stone columns in a natural soft clay. Stone column installation is modelled as an undrained expansion of a cylindrical cavity, using the finite element code PLAXIS that allows for large displacements. The properties of the soft clay correspond to Bothkennar clay, a soft Carse clay from Scotland (UK). The complexity of this material is simulated via two advanced recently developed constitutive formulations able to account for the soil structure, namely S-CLAY1 and S-CLAY1S. Modified Cam Clay model is also used for comparison purposes. The paper shows the new stress field and state parameters after column installation and the subsequent consolidation process. This sets the basis for including installation effects in studying the settlement reduction caused by stone columns.

\section{INTRODUCTION}

Stone columns are a common improvement technique for foundation of embankments or structures on soft soils. The gravel columns have a higher strength, stiffness and permeability than the natural soft soil. Therefore, they improve the bearing capacity and the stability of embankments and natural slopes, reduces the total and the differential settlements, accelerates the soil consolidation and reduces the liquefaction potential. Besides, column installation also modifies the properties of the surrounding natural soft soil. However, design of stone columns does not usually consider those installation effects and is typically based on their performance as rigid inclusions (Barksdale \& Bachus 1983, Balaam \& Booker 1985, Castro \& Sagaseta 2009). Some authors (Priebe 1995) account for a certain changes in the stress state during installation by using higher values of the earth pressure at rest than that for the natural soil. This paper discusses the alteration of the stress state and the initial state parameters of the soil caused by the column installation, which is nowadays one of the major concerns in an accurate design (Egan et al. 2008).

The study is restricted to those cases where columns are used in purely cohesive soils and the main effect is considered to be the cavity expansion induced by the vibrator penetration. Stone columns may also be used in soils that have an important granular fraction and in those cases, the densification caused by the vibration is probably the main in- stallation effect. That process is beyond the scope of the paper and has been analysed using mostly field measurements (Slocombe et al. 2000, Massarsch \& Fellenius 2002), as the numerical modelling is quite complicated (Arnold \& Herle 2009).

Experimental studies have shown some of the effects of column installation. For example, the increase of pore pressures and horizontal stresses, and the remoulding of the surrounding soil have been measured in the field (Watts et al. 2000, Watts et al. 2001, Kirsch 2004, Gäb et al. 2007, Castro \& Sagaseta 2012). There have also been attempts to investigate these effects through physical modelling of the process by means of centrifuge testing (Lee et al. 2004, Weber et al. 2010), but the soils used are reconstituted and hence, not fully representative of natural clays.

Numerical modelling is a useful tool that may help to derive some conclusions or recommendations about installation effects for column design, if the assumptions made in the model are validated by experimental measurements. Furthermore, few attempts (Kirsch 2006, Guetif et al. 2007) had been made in this field, using simple soil models. Therefore, the authors recently decided to study installation effects numerically using advance soil models to reproduce the behaviour of natural structured soft soils (Castro \& Karstunen 2010). The results were satisfactory, as they compared well with field measurements (e.g. Roy et al. 1981, Kirsch 2006, Serridge \& Sarsby 2008). 
Here, a detailed analysis of those numerical results once the excess pore pressures have been dissipated is presented. The new state of the soil that is obtained after column installation and full consolidation sets the basis of a future study of the influence that stone column installation has on the ground improvement, especially on the settlement reduction.

\section{NUMERICAL MODEL}

The finite element code Plaxis v9 (Brinkgreve 2008) was used to develop a numerical model of a reference problem to study installation effects of stone columns. The installation of only one stone column was considered, to simplify the problem to an axisymmetric two-dimensional geometry. In order to consider a realistic situation, properties of Bothkennar clay were used for the soft soil. The Bothkennar soft clay test site has been the subject of a number of comprehensive studies (Géotechnique Symposium in print 1992). The soil at Bothkennar consists of a firm to stiff silty clay crust about $1.0 \mathrm{~m}$ thick, which is underlain by about $19 \mathrm{~m}$ of soft clay. The ground water level is $1.0 \mathrm{~m}$ below the ground surface. Typically, in a structured soil, the in situ water content is close to the liquid limit.

Stone columns have been applied in Bothkennar clay (Watts et al. 2001, Serridge \& Sarsby 2008) or other Carse clays (Egan et al. 2008). For the numerical model in this paper, a column length of $10 \mathrm{~m}$ is used. The untreated clay underneath is not modelled, because the installation effects in this part of the soil are not particularly significant and furthermore, modelling the tip of the column may lead to some numerical instabilities.

The behaviour of Bothkennar clay was modelled using two advanced constitutive models, namely SCLAY1 (Wheeler et al. 2003) and S-CLAY1S (Karstunen et al. 2005). The Modified Cam Clay model (MCC) (Roscoe et al. 1958) is also used for comparison purposes. S-CLAY1 is a Cam clay type of model with an inclined yield surface to model inherent anisotropy, and a rotational component of hardening to model the development or erasure of fabric anisotropy during plastic straining. The SCLAY1S model accounts, additionally, for interparticle bonding and degradation of bonds, using an intrinsic yield surface and a hardening law describing destructuration as a function of plastic straining. The models have been implemented as User-defined soil models in Plaxis. An implementation that uses an implicit integration scheme (Sivasithamparam 2012) has been used, instead of an explicit previous version in Castro \& Karstunen (2010).

The values for S-CLAY1 model parameters (soil constants) and the initial state variables for Bothkennar clay are listed in Table 1 and 2, respectively. The additional parameters for S-CLAY1S are de- tailed in Table 3. S-CLAY1 model is formulated to be a hierarchical model, which reduces to MCC model by assuming $\mu=0$ and $\alpha_{0}=0$.

Table 1. S-CLAY1 parameters for Bothkennar clay.

\begin{tabular}{llcccccc}
\hline $\begin{array}{l}\text { depth } \\
(\mathrm{m})\end{array}$ & $\begin{array}{c}\gamma \\
\left(\mathrm{kN} / \mathrm{m}^{3}\right)\end{array}$ & $\kappa$ & $v^{\prime}$ & $\lambda$ & $M$ & $\mu$ & $\beta$ \\
\hline $0-1$ & 18.0 & 0.02 & 0.2 & 0.48 & 1.4 & 30 & 0.94 \\
$1-10$ & 16.5 & 0.02 & 0.2 & 0.48 & 1.4 & 30 & 0.94 \\
\hline
\end{tabular}

Table 2. S-CLAY1 initial state variables.

\begin{tabular}{llllll}
\hline $\begin{array}{l}\text { depth } \\
(\mathrm{m})\end{array}$ & $e_{0}$ & $\alpha_{0}$ & $\begin{array}{c}O C \\
R\end{array}$ & $\begin{array}{l}P O P \\
(\mathrm{kPa})\end{array}$ & $K_{0}$ \\
\hline $0-1$ & 1.1 & 0.539 & - & 30 & 1.35 \\
$1-10$ & 2 & 0.539 & 1.5 & - & 0.544 \\
\hline
\end{tabular}

Table 3. S-CLAY1S additional parameters.

\begin{tabular}{cccc}
\hline$\lambda_{i}$ & $\chi_{0}$ & $a$ & $b$ \\
\hline 0.18 & 5 & 11 & 0.2 \\
\hline
\end{tabular}

The geometry of the numerical model and the finite element mesh is shown in Figure 1. Parametric studies were carried out to check how wide the model should be to have a negligible influence of the outer boundary. Mesh sensitivity studies were performed to confirm the accuracy of the mesh. Calculations accounted for large displacements using the "updated mesh" option in Plaxis, which uses an updated Lagrangian formulation described by McMeeking \& Rice (1975).

Column installation is modelled as the expansion of a cylindrical cavity, which is considered to occur in undrained conditions, because columns are usually installed in a short period of time. The expansion of the cavity is modelled as a prescribed displacement from an initial radius, $a_{0}$, to a final one, $a_{f}$. Values of $a_{0}=0.1$ and $a_{f} 0.41 \mathrm{~m}$ represent the installation of a column with a radius of $r_{c}=0.4 \mathrm{~m}$ (Carter et al. 1979). After undrained expansion of the cavity, the generated excess pore pressures are dissipated through the permeable column and the surface. Further details of the numerical model can be found in Castro \& Karstunen (2010). The study here focuses on the results after full consolidation.

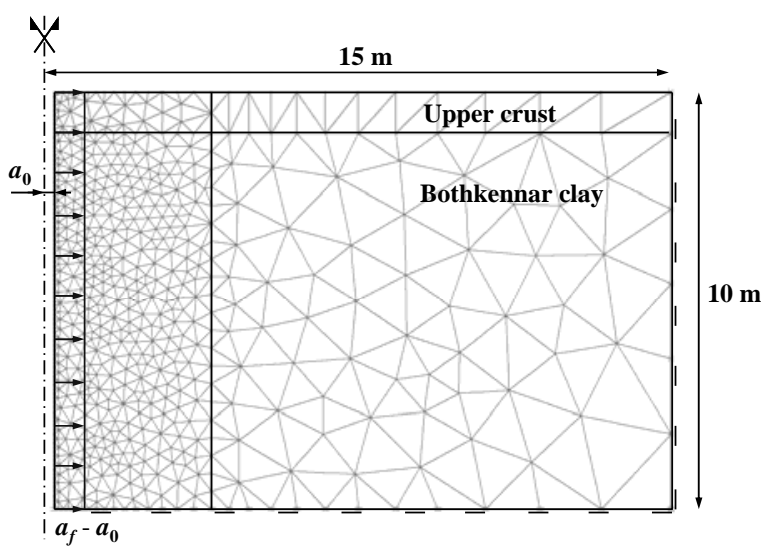

Figure 1. Model geometry and finite element mesh. 


\section{STRESS FIELD}

The aim is to study how the stress field in the natural soft soil around the column has changed. Horizontal stresses increase after column installation and, therefore, the changes in the stress field are usually considered through an increase in the lateral earth pressure coefficient, $K_{0}$. For example, Priebe (1995) already assumed in his method a value of $K_{0}=1$, which is higher that the initial value at rest for most soils. Kirsch (2006) presented field measurements of $K_{0}$ and showed that after column installation values between 1 and 1.7 times the initial one have been measured, depending on the distance to the column. Elshazly et al. (2006, 2008) have numerically backcalculated, from field measurements of loaddisplacement curves, values of $K_{0}$ between 0.7 and 2.5, with average values around 1.3.

Assuming an increase of the $K_{0}$ value is a useful approach for column design but it is just a simplification of the changes in the stress field during column installation. Figure 2 shows the results for the three soil models considered. The vertical, radial and hoop (circumferential) stresses may be still considered as the principal stresses as the shear stresses are negligible. The stress changes are different at different depths but they are directly proportional to the undrained shear strength, $c_{u}$, and therefore, also to the depth and the initial vertical stress in this case.

As expected, radial stresses increase near the column, but vertical and hoop stresses also change. Vertical stresses increase in the part nearest to the column, but for S-CLAY1S where vertical stress decreases because of destructuration. Interestingly, the hoop stresses are quite different to radial stresses. Three different areas may be distinguished: (1) an elastic one (beyond 11.5-13.5 column radii depending on the soil model) where soil behaviour is always elastic and hoop stresses decrease, (2) an area that is plastic during undrained expansion of the cavity but is not after consolidation, where vertical stresses change only slightly and (3) points that are on the yield surface also after consolidation (closer than 4.5-6 column radii), where densification and the increase in mean effective stresses are important.

Randolph et al. (1979) presented similar results for normally consolidated Boston Blue clay using the MCC model and a similar numerical model for driven piles. The results from this study with the MCC model are compared with those results (Figure $3)$. The comparison shows that, although there are differences in the OCR, the soil parameters and the initial stresses used in the current study, the values near the column/pile are very similar and well correlated with the initial undrained shear strength. The vertical and hoop stresses are around 3 times the initial value of the undrained shear strength and the radial stresses are between 4 and 5. Randolph et al. (1979) predicted a slightly higher value because their analysis is in perfect plane strain conditions while in the present analysis there are some vertical strains since the model realistically considers the soil surface. That also causes subtle differences in the shape of the curves. In the far field, the initial stresses of the present analysis are lower because of the lower value of the $\sigma_{z}^{\prime} / c_{u}$ relationship.
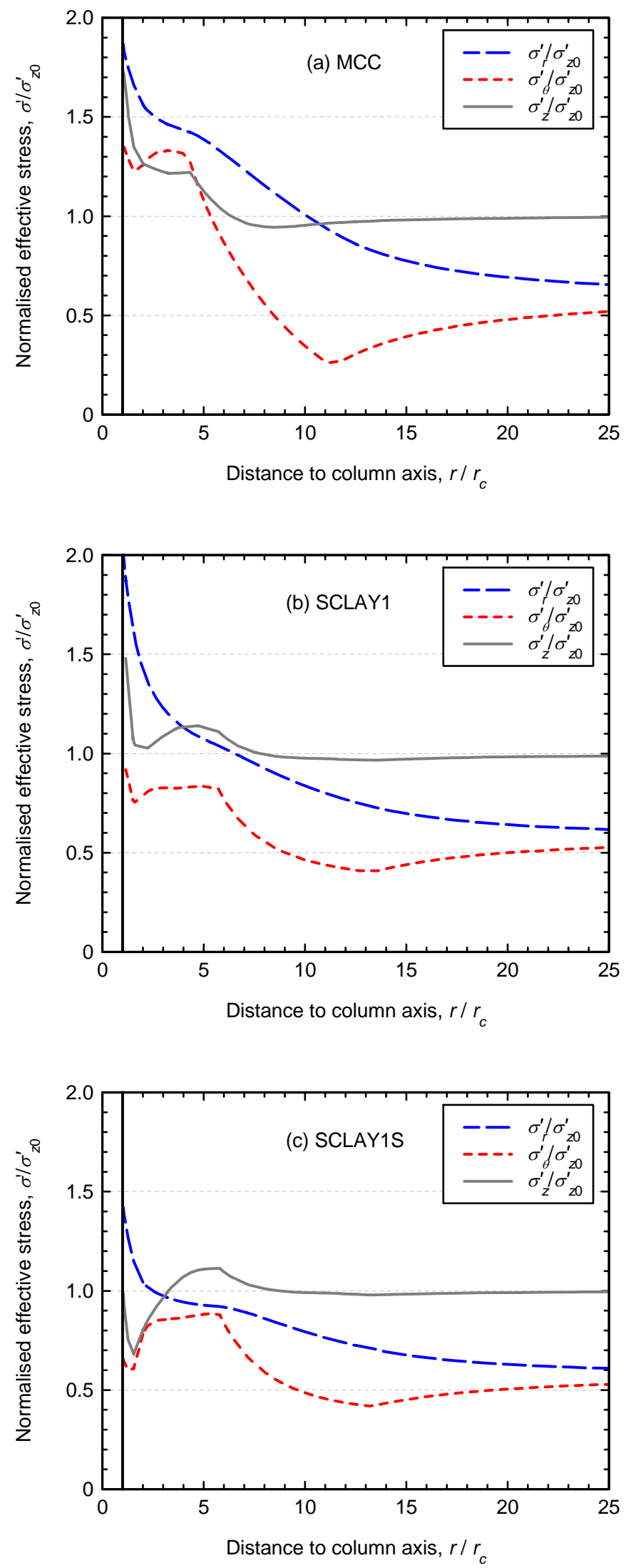

Figure 2. Effective stresses after column installation and full consolidation: (a) MCC, (b) S-CLAY1 and (c) S-CLAY1S. 

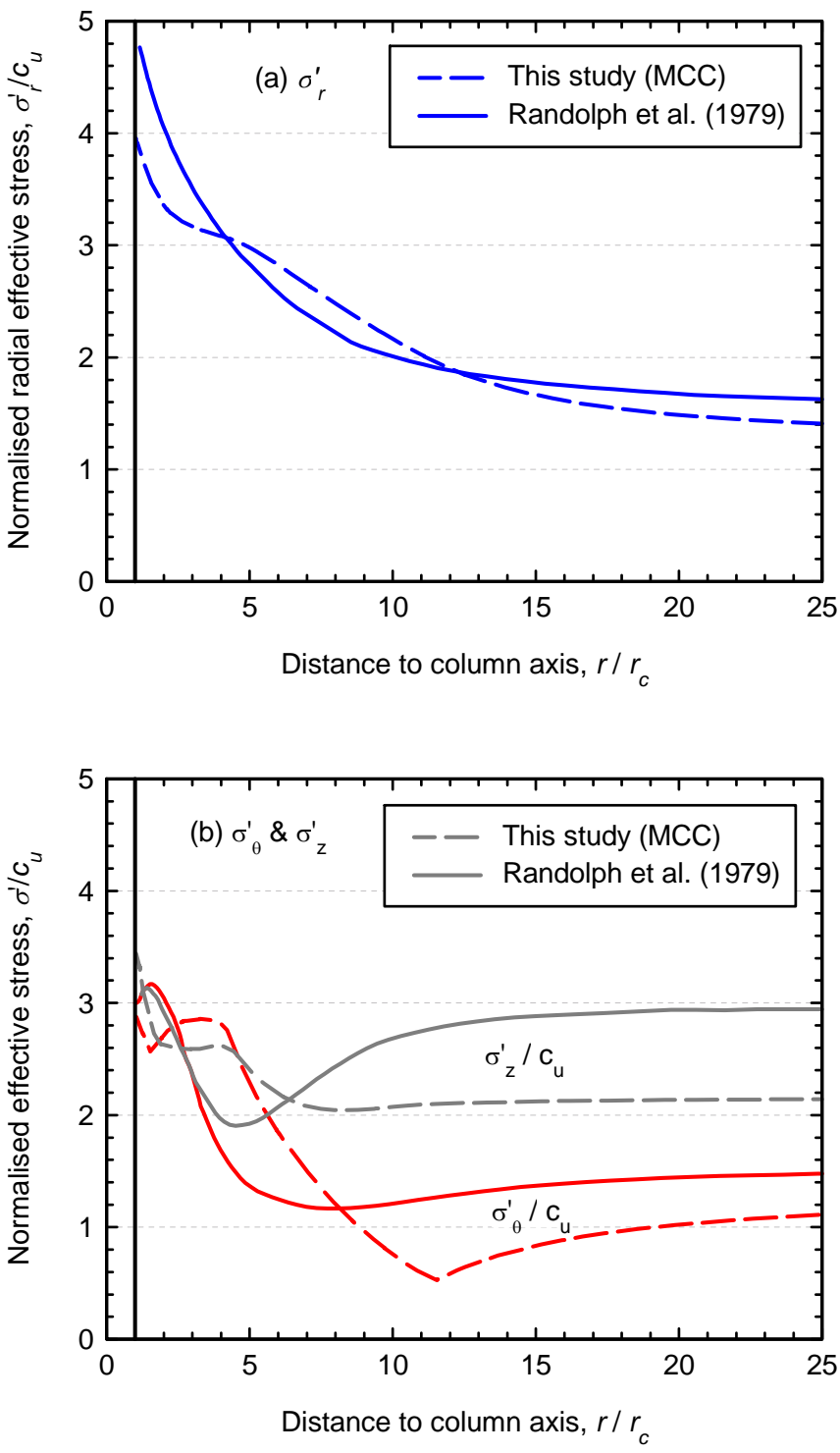

Figure 3. Effective stresses after column installation and full consolidation. Comparison with a previous study by Randolph et a. (1979) using MCC model.

The stress field described in Figure 2 is the basis for an ongoing study on the influence that the installation effects have on the settlement reduction. As the finite element mesh gets very distorted after column installation, it is advisable to input directly the stress field as the initial one in a new model. That requires curve fitting of the stress field and the modification of the soil model input parameters to allow for this particular initial stress field. Special care should be taken to ensure that equilibrium is fulfilled:

$\frac{\partial \sigma_{r}^{\prime}}{\partial r}+\frac{\sigma_{r}^{\prime}-\sigma^{\prime} \theta}{r}=0$

neglecting shear stresses to avoid unnecessary complexity.

In the present model, the installation of only one column is considered. Obviously, the installation of several columns will cause some interaction and overlapping of the stress changes.

\section{VOID RATIO AND OVERCONSOLIDATION}

Column installation not only alters the stress field but also the values for the state parameters of the soil, such as the void ratio (Figure 4 ). The void ratio decreases just near the column, less than 4.5-6 column radii (Zone 3 ). However, the densification is especially important in the area closer than 2 column radii (Zone 3a). Weber et al. (2010) measured a similar value of 2.5 column radii for the densification area. They fitted the data points of porosity and density using a hyperbolic function; a similar function may be here proposed to fit the void ratio:

$e=a_{3}-\frac{a_{1}}{r / r_{c}-a_{2}}$

The coefficient $a_{3}$ must be equal to the initial void ratio prior to column installation, in this case $a_{3}=2.0$. Furthermore, the coefficient $a_{2}$ must be lower than 1 because the void ratio cannot be negative in the soil domain.

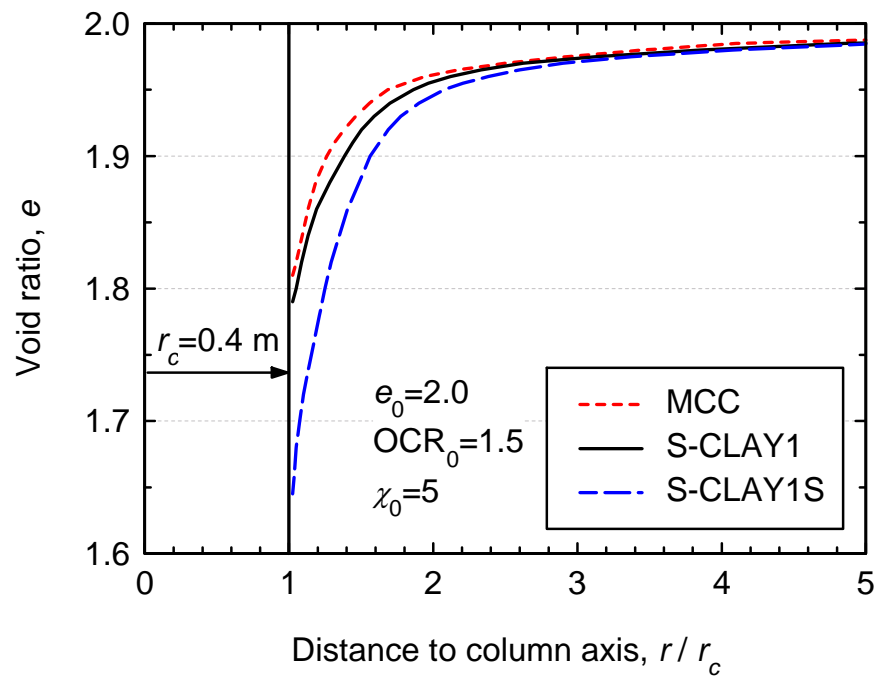

Figure 4. Void ratio after column installation and consolidation.

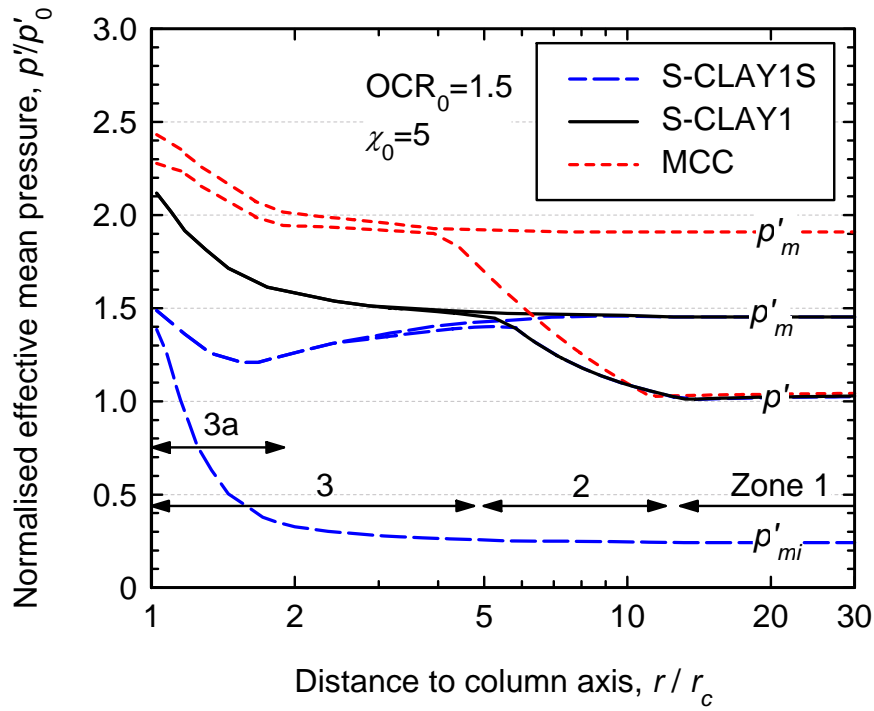


Figure 5. Size of the yield surface and mean effective stresses after column installation and consolidation.

The results for MCC and S-CLAY1 are quite similar but soil destructuration due to column installation causes a greater densification of the soil.

The value of the void ratio is directly related to the changes in the mean effective stresses and the mobilized soil stiffness. The mean effective stresses and the size of the yield surface, given by $p_{m}^{\prime}$, are plotted in Figure 5, where the distance to the column axis is in logarithmic scale to amplify the zone of interest near the column. The different zones previously distinguished are also visible here: (1) far from the column, the mean effective stresses does not change, (2) the mean effective stress increases but without expanding the yield surface because the overconsolidation ratio is $\mathrm{OCR}=1.5$, (3) the current stress point is on the yield surface and (3a) the yield surface is notably expanded through strain hardening, $p_{m}^{\prime}$ increases. Note that the extension of these zones is slightly different depending on the soil model. The current mean effective stress, $p^{\prime}$, do not necessarily coincide with $p_{m}^{\prime}$ when the point is on the yield surface because $p_{m}^{\prime}$ is the mean effective stress at the apex of the yield surface on the right (Wheeler et al. 2003). For MCC, the differences are noticeable but for S-CLAY1 type models, they are very similar. The relative expansion of the yield surface is similar for MCC and S-CLAY1, which explains the similar results for the void ratio. For $\mathrm{S}$ CLAY1S, the intrinsic yield surface, $p_{m i}^{\prime}$, is significantly expanded in Zone 3 a.

For normal column spacings, the soil is in Zone 3 , but the densification or the strain hardening is only important in Zone 3a, i.e. for closely spaced columns.

The changes in the stress field and the initial state variables, if anisotropy and destructuration are not considered, have an influence on the ground improvement through the following features: (a) the increase in the radial stress, which has a positive effect on the improvement as the column is better laterally confined and (b) the increase in the mean effective stresses, which may be positive if the yield surface is expanded and the soil hardens (Zone 3a) or may be negative if the yield surface is not clearly expanded as the soil loses its overconsolidation and for a subsequent loading process, there is not an elastic region anymore and the soil has not hardened either.

\section{ANISOTROPY}

The advanced soil models S-CLAY1 and SCLAY1S can used to reproduce the changes in soil fabric due to column installation. The inclination of the yield surface changes, as shown in Figure 6, where the components of the fabric tensor, $\left\{\alpha_{i}\right\}$, are plotted. The two models predict almost identical changes in anisotropy.

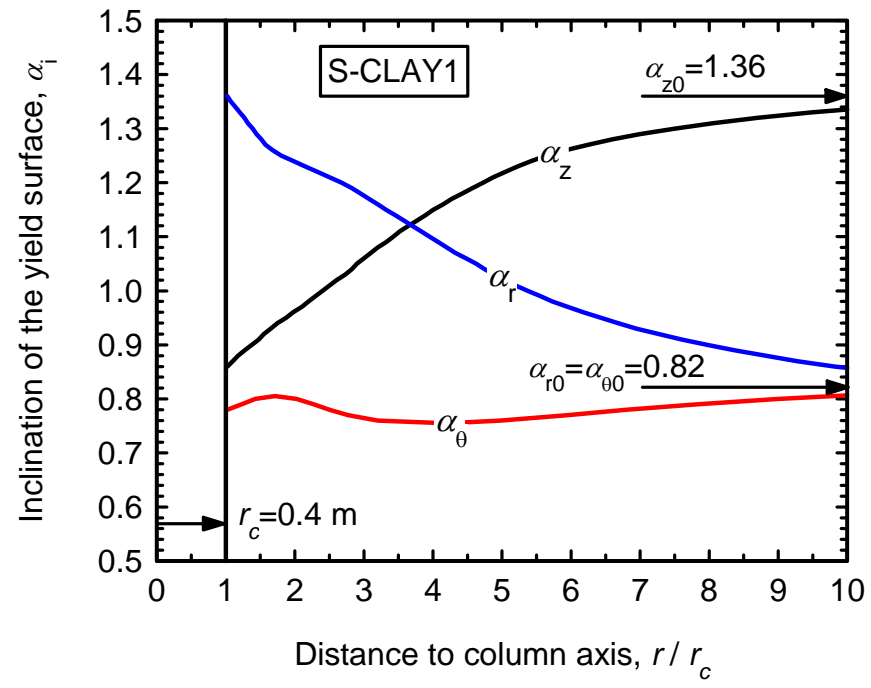

Figure 6. Components of the fabric tensor after column installation and consolidation in S-CLAY1.
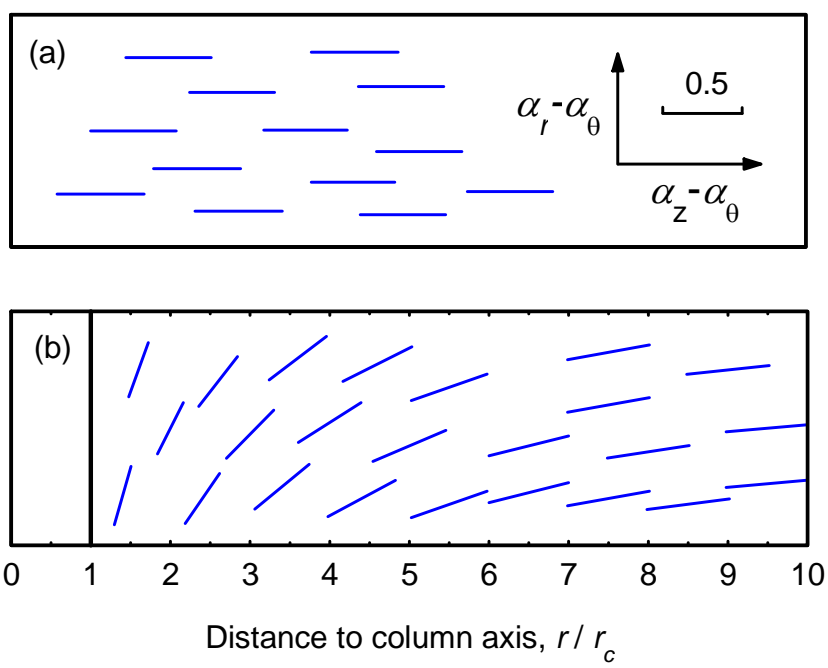

Figure 7. Visualization of the soil fabric: (a) before column installation and (b) after column installation and consolidation.

To help to visualize the changes in soil fabric, Figure 7 shows the $\left(\alpha_{z}-\alpha_{\theta}, \alpha_{r}-\alpha_{\theta}\right)$ vector in arbitrary points. This vector changes from horizontal direction for an initial vertical cross anisotropy towards a nearly vertical one for radial cross anisotropy. Its length is equal to $\alpha_{0}=0.539$ for the initial situation and changes only slightly.

The components of the fabric tensor after column installation and consolidation (Figure 6) must be input as the initial values to study the influence that those changes have on the settlement reduction. That requires curve fitting of those components. By definition of the fabric tensor, the fitting of those components must fulfilled that

$\alpha_{r}+\alpha_{\theta}+\alpha_{z}=3$ 
So, for the sake of simplicity, it seems sensible to keep $\alpha_{\theta}$ constant and decrease $\alpha_{z}$ the same amount that $\alpha_{r}$ increases.

\section{CONCLUSIONS}

The paper describes the changes in soil stresses and initial state variables after stone column installation. They will be used as the initial ones in an on-going study of the influence that those installation effects have on the settlement reduction. The stresses and the void ratio may be fitted by hyperbolic curves that fulfil some conditions, such as equilibrium.

The stresses near the column are related to the initial undrained shear strength of the soil. For normal column spacings, the soil is in a plastic state, which may be negative for a subsequent loading process because it has lost its overconsolidation or positive if the yield surface has been notably expanded (strain hardening). The latter case occurs for closely spaced columns. In any case, the increase of the radial stress improves the lateral confinement of the column. The initial vertical cross anisotropy of the soil changes towards a radial one when approaching the soilcolumn interface.

ACKNOWLEDGEMENTS: The research was carried out as part of a GEO-INSTALL project by the European Community through the programme Marie Curie IndustryAcademia Partnerships and Pathways (PIAP-GA-2009230638).

\section{REFERENCES}

Arnold, M. \& Herle, I. 2009. Comparison of vibrocompaction methods by numerical simulations. International Journal for Numerical and Analytical Methods in Geomechanics 33(16): 1823-1838.

Balaam, N.P. \& Booker, J.R. 1985. Effect of stone column yield on settlement of rigid foundations in stabilized clay. International Journal for Numerical and Analytical Methods in Geomechanics 9(4): 331-351.

Barksdale, R.D. \& Bachus, R.C. 1983. Design and construction of stone columns. National Technical Information Service Report FHWA/RD-83/026, Federal Highway Administration, Springfield, Virginia.

Brinkgreve, R.B.J. 2008. Plaxis 2D - Version 9. Plaxis, Delft.

Carter, J.P., Randolph, M.F. \& Wroth, C.P. 1979. Stress and pore pressure changes in clay during and after the expansion of a cylindrical cavity. International Journal for $\mathrm{Nu}$ merical and Analytical Methods in Geomechanics 3(4): 305-322.

Castro, J. \& Karstunen, M. 2010. Numerical simulations of stone column installation. Canadian Geotechnical Journal 47(10): 1127-1138.

Castro, J. \& Sagaseta, C. 2009. Consolidation around stone columns. Influence of column deformation. International Journal for Numerical and Analytical Methods in Geomechanics 33(7): 851-877.
Castro, J. \& Sagaseta, C. 2012. Pore pressure during stone column installation. Proceedings of ICE - Ground improvement 165(2): 97-109.

Egan, D., Scott, W. \& McCabe, B. 2008. Installation effects of vibro replacement stone columns in soft clay. In Karstunen and Leoni (eds.) Geotechnics of Soft Soils - Focus on Ground Improvement, Glasgow, 3-5 September 2008. Taylor and Francis: London, pp. 23-29.

Elshazly, H.A., Hafez, D. \& Mosaad, M. 2006. Back calculating vibro-installation stresses in stone columns reinforced grounds. Proceedings of ICE - Ground improvement 10(2): 47-53.

Elshazly, H.A., Elkasabgy, M. \& Elleboudy, A. 2008. Effect of inter-column spacing on soil stresses due to vibro-installed stone columns: interesting findings. Journal of Geotechnical and Geological Engineering 26: 225-236.

Gäb, M., Schweiger, H.F., Thurner, R. \& Adam, D. 2007. Field trial to investigate the performance of a floating stone column foundation. In Proc. of the $14^{\text {th }}$ European Conf. Soil Mech. Geotech. Eng., Madrid, 24-27 September 2007. Millpress: Amsterdam, pp. 1311-1316.

Géotechnique Symposium in print. 1992. Bothkennar soft clay test site: characterisation and lessons learned. Géotechnique 42(2).

Guetif, Z., Bouassida, M. \& Debats, J.M. 2007. Improved soft clay characteristics due to stone column installation. Computers and Geotechnics 34(2): 104-111.

Karstunen, M., Krenn, H., Wheeler, S.J., Koskinen, M. \& Zentar, R. 2005. Effect of anisotropy and destructuration on the behaviour of Murro test embankment. ASCE International Journal of Geomechanics 5(2): 87-97.

Kirsch, F. 2004. Experimentelle und numerische Untersuchungen zum Tragverthalten von Rüttelstopfsäulengruppen. Dissertation, Technische Universität Braunschweig.

Kirsch, F. 2006. Vibro stone column installation and its effect on ground improvement. In Proc. of Numerical Modelling of Construction Processes in Geotechnical Engineering for Urban Environment, Bochum, Germany, 23-24 March 2006. Taylor and Francis: London, pp. 115-124.

Lee, F.H., Juneja, A. \& Tan, T.S. 2004. Stress and pore pressure changes due to sand compaction pile installation in soft clay. Géotechnique 54(1): 1-16.

Massarsch, K.R. \& Fellenius, B.H. 2002. Vibratory compaction of coarse-grained soils. Canadian Geotechnical Journal 39(3): 695-709.

McMeeking, R.M. \& Rice, J.R. 1975. Finite-element formulations for problems of large elastic-plastic deformation. International Journal of Solids and Structures 11: 606-616.

Priebe, H.J. 1995. Design of vibro replacement. Ground Engineering 28(10): 31-37.

Randolph, M.F., Carter, J.P. \& Wroth, C.P. 1979. Driven piles in clay-the effects of installation and subsequent consolidation. Géotechnique 29(4): 361-393.

Roscoe, K.H., Schofield, A.N. \& Wroth, C.P. 1958. On the yielding of soils. Géotechnique 8(1): 22-53.

Roy, M., Blanchet, R., Tavenas, F. \& La Rochelle, P. 1981. Behaviour of a sensitive clay during pile driving. Canadian Geotechnical Journal 18(2): 67-85.

Sivasithamparam, N. (2012). Development and implementation of advanced soft soil models in finite elements. $\mathrm{PhD}$ thesis, University of Strathclyde, Scotland.

Slocombe, B.C., Bell, A.L. \& Baez, J.I. 2000. The densification of granular soil using Vibro methods. Géotechnique 50(6): 715-726.

Watts, K.S., Chown, R.C. \& Serridge, C.J. 2001. Vibro stone columns in soft clay: A trial to study the influence of column installation on foundation performance. In Proc. of the $15^{\text {th }}$ Int. Conf. Soil Mech. Geotech. Eng., Istanbul, 28-31 August 2001. Taylor and Francis: London, pp. 1867-1870. 
Watts, K.S., Johnson, D., Wood, L.A. \& Saadi, A. 2000. An instrumented trial of vibro ground treatment supporting strip foundations in a variable fill. Géotechnique 50(6): 699-708.

Weber, T.M., Plötze, M., Laue, J., Peschke, G. \& Springman, S.M. 2010. Smear zone identification and soil properties around stone columns constructed in-flight in centrifuge model tests. Géotechnique 60(3): 197-206.

Wheeler, S.J., Näätänen, A., Karstunen, K. \& Lojander, M. 2003. An anisotropic elastoplastic model for soft clays. $\mathrm{Ca}$ nadian Geotechnical Journal 40(2): 403-418. 